\title{
Curriculum development in sexual health/ reproductive health in Turkey
}

\section{Gul Pinar ${ }^{1}$, Ziyafet Hanoglu², and Lale Algier ${ }^{3}$}

Summary: An examination of the problems experienced in the area of sexual health/reproductive health (SH/RH) in Turkey reveals that women confront many problems, particularly during their reproductive years. To resolve these problems it is clear that the participation of nurses, who are such a large part of the health care workforce, cannot be ignored. Accordingly, this study was conducted for the purpose of improving the curriculum and students' clinical skills in SH/ RH at Baskent University Health Sciences Faculty Nursing and Health Services Division. In this study, the current SH/RH curriculum was reviewed, needs were determined and the number of hours and distribution of topics in the curriculum were revised. More emphasis was given to active educational methods that will ensure the participation of students in practical classes as well as including more visual educational materials. Modern educational models that facilitate learning by doing were included in the curriculum. Students were assessed using indicators defining practice. According to the assessment results, students achieved a success level between $30 \%$ and $80 \%$, and students' opinions about their skills laboratory practice and clinical practice indicated positively that the majority (90\%) achieved the practice learning goals.

Key words: quality management system; nursing education; reproductive health

1. Assistant Professor, Baskent University Health Science Faculty Nursing Department

2. Baskent University Health Science Faculty Nursing Department

3. Professor, Baskent University Health Science Faculty Nursing Department

Address for correspondence: Baskent University, HSF, Dept. of Nursing, Ankara, Turkey.gpinar@baskent.edu.tr

58 Journal of Practice Teaching \& Learning 8(2) 2008, pp.58-74. DOI: 10.1921/81133. (C) wEb 


\section{Introduction}

There are considerable improvements related to the development of SH/RH service quality in our country parallel to the developments at international level. The Republic of Turkey Ministry of Health (TRHM) has carried out subject-related educational and research projects in coordination with national and international organisations over the past 40 years. Despite positive developments, health organisation statistics and scientific research indicates that mother-child death is still at a high rate in our country. Today, health care in Turkey has improved compared to the past but it has still not reached the desired quality. To make better this situation, it is posited that nurses have important roles in the health sector. One of the most important factors for increasing service quality is to educate nurses as knowledgeable, skilled, experienced and meeting the needs in their field (TRHM, 2005).

It is important, therefore, to ensure that students acquire increased knowledge and skills in university-level health education. In Turkey, $\mathrm{SH} / \mathrm{RH}$ education does take place in the current nursing school curricula, but it is not conducted at sufficient depth (Bebeis et al., 2003). Therefore, Baskent University Faculty of Health Sciences Department of Nursing and Health Services initiated a project for the purpose of increasing students' knowledge and skills in the subjects related to SH/ $\mathrm{RH}$. The purpose of the study reported in this paper is to examine the $\mathrm{SH} / \mathrm{RH}$ curriculum to educate nurses and ensure they have enough knowledge and skills to work with the current problems in the fields of SH/RH in Turkey.

\section{The health care context in Turkey}

The population of the Turkish Republic is approximately 70 million, $65 \%$ of whom live in cities and $35 \%$ of whom live in rural areas. One third of the population is 15 years and under and approximately $6 \%$ are 65 years and older. Turkey varies in social and cultural structure, with 'modern' and 'traditional' life styles co-existing simultaneously within the society. For the inhabitants of metropolitan areas, daily life is similar to that in Western countries. On the other hand, people living on the outskirts of urban areas and rural settlements are relatively

59 Journal of Practice Teaching \& Learning 8(2) 2008, pp.58-74. DOI: 10.1921/81133. @ wEb 
conservative and traditional. Family ties are still strong and influential in the formation of values, attitudes, aspirations, and goals. Although laws are considered to be quite liberal in respect of gender equality, patriarchal ideology characterizes the social life in many ways, involving Turkey's young male population in reproductive health issues remains a challenge as does changing attitudes amongst young people of both sexes about violence against women (TDHS, 2003).

In spite of liberal policies, social and economic parity of women lags far behind their legal rights. Two in five women make their own decisions about the use of their earnings, while one-half of women decide jointly with their husband or someone else (Akin, 2003). Women's exposure to domestic violence and harassment is still common. Turkey launched a campaign on 'Violence Against Women' in 2004 with support from the United Nations Population Fund. Using data from UNFPA (2004), surveys have revealed that 63 percent of young women aged 15-19 believe domestic violence towards female spouses is justified in some cases. This indicates a need for training and better awareness of the rights and responsibilities for both sexes (UNFPA, 2004).

In the last 20-30 years there has been a significant decrease in the fertility rate. At the beginning of the 1970s the fertility rate was five children per women but it has dropped to 2.2 since 2000. Childbearing in Turkey is concentrated in the age group 20-29; an average woman in Turkey will have one child by age 25 , and two children by age 30 . The fertility level declines sharply after age 30 and childbearing is negligible for women in their forties. Education has an important impact on fertility. Women who have no education have 1.3 more children than the women with first level primary education and 2.3 children more than the women with at least high school education (Akin, 2003). The median age at first marriage is 20 for women age 25-49. While overall contraceptive prevalence is high at 64 percent, the use of modern contraceptives is only 38 percent. The overall unmet need for family planning follows a declining trend with increasing age. There is a wider variety of contraceptives available, but abortion rates remain high and the quality of counselling services still needs to be improved. Every year 1,400 mothers die as a result of childbirth-related complications in Turkey and 29 of every 1000 infants do not live to their first birthday. Every year approximately two million women become pregnant, but of these pregnancies only 1,371,000 result in live births. The infant

60 Journal of Practice Teaching \& Learning 8(2) 2008, pp.58-74. DOI: 10.1921/81133. () wEb 
mortality rate in the rural areas is about 70 percent higher than in urban areas. Infant and under-five mortality rates are higher than the national average in the North and East regions. Overall, more than half of women received at least four antenatal care appointments. However, the timing and the number of visits made for antenatal care varies by place of residence. Median durations for exclusive breastfeeding are very short, around less than one month for all subgroups. Male children, children living in rural areas, in the East region, and those whose mothers have no education are likely to have a somewhat longer period of full breastfeeding. For these reasons, the mortality rate from childbirth related causes in women at a fertile age is 10-15 times higher than the rate in developed countries. To decrease this rate it is necessary to give more information and skills to university students in health education. In Turkey, university level education uses modern teaching methods, but students may not be given enough education in practice (TDHS, 2003).

The TRHM is vested with the authority to provide medical care and preventive health services, train health personnel, provide pre-service and in-service training, establish and operate health institutions and authorize the establishment and oversee medical institutions by other public and private organisations. The organisation of the current health care system in Turkey is very complicated. Many official and private institutions provide health care. All of them provide curative health care but the TRHM provides both curative and preventive services. Primary health care services in Turkey are organised under a law dated 1961, which aimed to provide more and better qualified health care services, especially for the rural community. This law states that health care services are one of the main responsibilities of the government. Under this law, health centres and health posts are the primary health care institutions organised to match geographical distribution. The basic (primary) health units are health centres and health posts at the village level. According to the legislation, health posts staffed by a midwife serve a population of 2,500-3,000 in rural areas. There are 11,888 health posts in Turkey. Health centres serve a population of 5,000 - 10,000 and are staffed by a team consisting of at least a physician, a nurse, a midwife, a social worker, a health technician, driver, and a medical secretary. The main functions of health centres, as primary health care services, are the prevention and treatment of communicable diseases,

61 Journal of Practice Teaching \& Learning 8(2) 2008, pp.58-74. DOI: 10.1921/81133. @ wËb 
immunisation, maternal and child health services, family planning, public health education, environmental health, diagnosis and treatment of cases subject to primary level of care and the collection of statistical data (TRHM, 2004).

In secondary and tertiary care, hospital services are provided by the TRHM, the Ministry of Defence, the Ministry of Labour and Social Security, some State Economic Enterprises, universities and the private sector. Although there is a structure of primary, secondary and tertiary health care institutions in Turkey, people are free to choose their first contact point, except for those who hold a green card given by the government that covers the healthcare costs of people in poverty. Tertiary health care institutions such as university hospitals can be chosen as a first contact point in certain consequences. The mechanism proposed for financing the provision of services is the General Health Insurance Scheme (GHIS). Considerable socioeconomic variations exist in Turkey that influence access to health care. The GHIS aims to ensure equity by achieving universal coverage for all citizens who are not currently covered by social security schemes (Akin, 2003; TRHM, 2005).

In accordance with an agreement between the TRHM and the European Commission the 'Turkish Reproductive Health Programme' (TRHP) was put into practice for the purpose of improving the SH/ RH of Turkey's female population in particular as well as that of young people and to increase women's use of services. The TRHP was based on national health data, decisions of the 1994 Cairo International Population and Development Conference, and the 1998 Women's Health and Family Planning National Strategic Action Plan. The topics that are included in the programme are safe motherhood, family planning, sexually transmitted diseases, adolescents' reproductive and sexual health, and emergency obstetric care (Neyzi and Yolsal, 2002).

The general aim of the 'Strengthening the Educational Capacity for SH/RH before Graduation Project', a sub-project of the TRHP, is to have a part in strengthening SH/RH education before graduation for medical, midwifery, and nursing students in Turkey, bringing it into compliance with European Union law and regulations (TRHM, 2004; MHECDCP, 2005).

62 Journal of Practice Teaching \& Learning 8(2) 2008, pp.58-74. DOI: 10.1921/81133. ( $w \mathcal{E} b$ 


\section{Nurse education in Turkey}

In Turkey, development in nursing education has been offset by some negative events. Nursing education became the responsibility of the TRHM and Higher Education Council. In 1996, a second protocol was signed by the TRHM, with the result that nursing education was increased in length to four years, and control of the health high schools was given over to administration by the universities (Aksayan and Cimete, 2000).

As a result, there are presently two groups of trained and educated nurses: one group from universities and the other from high schools. Nurses with two different educational backgrounds have to share the same title and responsibilities when they graduate. The insistence of the TRHM on educating nurses at the high school level is the result of political decisions, not the nurses' decisions, and it is considered to be one of the biggest obstacles to professional development. According to the Turkish Nursing Law of 1954, the authority and responsibility of nurses graduating from the aforementioned different nursing programmes is not different based on educational level. This lack of difference granted to baccalaureate degree nurses was of concern to them and had a negative effect on the quality of nursing service and the harmony and cooperation between practising nurses. The minority group of university graduate nurses have less power to effect positive change in raising the standard of nursing care. Nursing education consists of theoretical knowledge combined with clinical practice. Clinical practice is seen to increase nursing students' knowledge, and their capacity to synthesise theoretical knowledge and nursing care. But, sometimes there is a lack of quality clinical settings for students. These difficulties include nurses who lack clinical teaching training, insufficient co-operation between nursing schools and hospitals, the paucity of clinical nurse specialists, and nurse lecturers being insufficiently qualified to supervise clinical practice properly (NNECP, 2003; Ulusoy, 1998).

Turkey's efforts to join the European Union and the need to adapt to European standards have created a new situation (as with other professions). The European Union conditions state that nursing education requires at least three years and 4600 hours. Nursing education is already four years duration, in Turkey. Efforts to develop a core curriculum in nursing began in 2002. The aim of these efforts was

63 Journal of Practice Teaching \& Learning 8(2) 2008, pp.58-74. DOI: 10.1921/81133. @ wEb 
to determine the minimum standards in terms of theory and skills for nursing graduates. (All-in-all, the aim was to provide safety and holistic care to the community by research minded, skilful nurses.) In this core curriculum, adapted from European Union criteria in terms of content and duration (4600 hours). In our country, due to anticipated accession to the European Union in the near future, attention is being paid to the free circulation of professionals and to meeting the changing healthcare needs at international standards. Professional definitions and roles have also been improved and education programmes to realise them are also being improved (NNECP, 2003; Aksayan and Cimete, 2000).

\section{Nursing education in Baskent University}

Baskent University School of Nursing was established in 1994 with a baccalaureate programme. In 2000, the Health Science Faculty was established which included the nursing and other departments related to health science such as physical therapy, nutrition and dietetics. The Department of Nursing and Health Services is the first and the only nursing school within a faculty in Turkey. Along with this change, we restructured the nursing curriculum based on medical model and started a new curriculum based on integration in 2000. In 2005, we revised our nursing curriculum according to WHO European Strategy for Nursing Education in terms of duration (4600 hours). The aim of our programme is to prepare students for being able to take new roles within the multidisciplinary team and continually changing health system and to develop their problem solving and critical thinking skills.

Our division is the first nursing division in Turkey to provide education within a university faculty. The division curriculum is consistent with a horizontally and vertically integrated system. According to this system, a student does not just learn nursing as treating illnesses but as considering the whole person. In an integrated system subjects are spread over the years of education. A sequence is followed from health promotion and development to the care of individuals with health problems and from simple health problems to complex health problems. Active teaching methods are also used as an educational methodology. The same approach and methods are used for SH/RH subjects. We believe that learning is made easier for the students participating in the learning process when they accept responsibility for this process. We

64 Journal of Practice Teaching \& Learning 8(2) 2008, pp.58-74. DOI: 10.1921/81133. @ wEb 
give scenarios about the teaching units to the students in the nursing lectures. In our group studies, facilitators expect the students to identify the problems and make the nursing diagnosis and nursing interventions in the scenarios. This method enables the students to concentrate not on the illness alone but on specific health problems and individual needs, to assess their own learning needs, to think critically and to analyse the knowledge gained.

In clinical practice, the students gather the data with the client and family interview method by using the assessment forms developed according to Gordon's Functional Health Patterns (Gordon, 2002; Olds et al., 2004; Nettina and Mills, 2006). The data are supported by physical assessment findings, diagnostic tests results and the nursing diagnoses are assessed.

Baskent University Management made the decision to create and implement a nursing students' sexual health - reproductive health information and skills development project by providing financial resources in the university budget for the purpose of training health care personnel who, following graduation from university, would be employed in various health care facilities in the country. The intention being to provide nurses with the necessary SH/RH knowledge and skills to offer services to the public, to provide continuity in the health care provided and to contribute to the UNFPA aims described above. This paper now describes the evaluation of the project for nurse education.

\section{The study}

The project had the following three aims:

- to examine the content of the current SH/RH education programme and make revisions and update where necessary

- to increase the students' skills at monitoring and assessing in the $\mathrm{SH} / \mathrm{RH}$ area

- to share experiences obtained with Baskent University and other interested health facilities at universities in other provinces in Turkey

65 Journal of Practice Teaching \& Learning 8(2) 2008, pp.58-74. DOI: 10.1921/81133. @ wËb 


\section{Method}

The study activities were carried out by an education team leader with authority and responsibility to make decisions and an education team formed according to area of specialty and experience. During the preparation stage of the study the educators on the team examined the Munich Declaration, various documents from the World Health Organisation, and, in particular, the 'European Union Standards for Nursing and Midwifery: Information for Member Countries' documents, European Union Nursing and Midwifery Directives, International Nursing Congress definitions, and 'Turkish Health Reform Strategies for Revision'(AMEE, 2005; WHO, 2000; Munich Declaration, 2000; UNFPA, 2004; TRHM, 2005; Bebeis et al., 2003). In addition to these, the European Union's education standards, prior to graduation, for nursing education on the subject of reproductive health (RH), RH curricula developed by international organizations, general international standards determined for nursing education, various education programmes and the Nursing National Core Education Programme (NNCEP) prepared for baccalaureate nursing programmes in Turkey were also reviewed (WHO, 2001; NNCEP, 2003; IPPF, 2005; RCOG, 2001; MHECDCP, 2005). Furthermore, the members of the education team reviewed the division's needs/expectations and the models currently being used in SH/RH education and prepared an educational booklet for skills laboratory educators. The team examined the mechanism for monitoring-assessment in the current health system in the country and conducted studies to ensure that activities would be able to continue and that there would be continuity in improvement activities.

As a result of the studies conducted in the preparation stage of the project a SH/RH education curriculum was created. Measurable indicators that accorded with the study aim and goals and confirmation resources were determined and the curriculum was put into effect. Significant changes were not made in the distribution of SH/RH topics throughout the four-year nursing programme or in the theoretical information. However, revisions were made in clinical skills laboratory practice and other practice settings (clinical and field) to increase students' skills. The number of hours for skills and practice was raised, and educational methods designed to support students' active

66 Journal of Practice Teaching \& Learning 8(2) 2008, pp.58-74. DOI: 10.1921/81133. (o wEb 
participation were used (demonstration, role playing, case study, station system, group study, brain storming, seminars).

In our division, curriculum subjects related to SH/RH anatomy and physiology and basic SH/RH concepts are taught in the first year, safe motherhood, family planning and adolescent health topics in the second year, emergency obstetrics and sexually transmitted diseases in the third year. In addition, skills laboratory practice and clinical-field practice related to these topics are also done. In the fourth year there is an internship clinical-field practice for all topics included in SH/RH.

\section{Revised Areas}

\section{SH/RH education programme}

According to the study goals the education programme was focused on the five areas frequently faced by graduates in the health care facilities where they work. These included safe motherhood, urgent obstetrics, family planning, STD, adolescent SH/RH. In addition, the basic concepts in reproductive health (reproductive rights, sexuality, sexual health, women's status and relationship with health, domestic violence and violence against women, social gender and effect of health) were integrated into related courses by creating educational modules. These subjects were distributed over the four year curriculum as appropriately integrated models that were practised in the division. Different modules were considered for different courses. The revised SH/RH education programme began with first and second year students in the 2005-2006 school year.

\section{Educational material:}

Educational materials were prepared for educators and students to use in SH/RH training. This included guidelines on SH/RH topics for the purpose of supporting nurse education. The guidelines to the 'Educator Notes (Theoretical Framework)' contain information for the benefit of the educator and participants. It sets out the areas that must be learned. Importance was given to supporting each subject with visual materials. At this stage, cooperation with the Baskent University Fine Art Design and Architecture Faculty enriched the visual materials for the theoretical guidelines.

67 Journal of Practice Teaching \& Learning 8(2) 2008, pp.58-74. DOI: 10.1921/81133. @ wËb 
The prepared education material utilised within the class was focused on the individual. Every session in the guidelines included the following sections:

- Plan

- Practice-Activities

- Assessment

Each education plan for the included subjects contained a summary of the sessions and the goals, objectives, content, tools-instruments, length, method and assessment sections. In addition, in every guideline there were pre-tests and post-tests to be given to the students before and after the session.

In nursing education, it is foundational for information, skills and attitudes to be acquired under the guidance of the educator for the development of desired behaviours in the student. Nursing is a profession that has both theoretical and practical learning experiences and requires that students can transfer theoretical information into practical skills. In nursing education the target is for students to acquire competency in cognitive, sensory and psychomotor areas. Adult learning methods were kept in mind while preparing the guidelines and methods to ensure students' active participation were used.

Behaviours associated with the area of cognitive skill in nursing education are easier to acquire and measure, but there is a need for standards to facilitate learning and to ensure objective measurement and assessment of psychomotor behaviours and, consequently, there is a need for the creation of and use of measurement tools. Based on this need the 'Educator's Practice Guide' was prepared for the purpose of helping the educators to develop students' skills associated with working with SH/RH. The guidelines have two sections. The curriculum's SH/ $\mathrm{RH}$ practices are included in the first section. In the second section there are guidelines for skill development and assessment used to develop skills in students in SH/RH subjects, data collection forms and observation forms.

\section{Skills and Practice}

Within the scope of the skills and practice activities aspect of the study the laboratory space, manikins, models, instruments and tools were revised and improved. The area for the skills laboratory before the

68 Journal of Practice Teaching \& Learning 8(2) 2008, pp.58-74. DOI: 10.1921/81133. @ wEb 
project was $42 \mathrm{~m}^{2}$ which was more than doubled to an area of $88 \mathrm{~m}^{2}$. The number of SH/RH anatomic models, manikins and pictures, which we began to use in our division in 1993, were increased during the study and today the skills laboratory has been enriched with modern education models, manikins and pictures. The revision of the skills laboratory was financed by the office of the Dean of Baskent University.

The number of practice hours associated with SH/RH subjects was increased under the scope of the study. The hours for role playing and demonstration in the theoretical section of learning and the skills laboratory hours were increased. Before the study the SH/RH content in the curriculum was 43 hours theory, four hours skills laboratory practice and 348 hours clinical and field practice. With curricular revisions in the study, the theory hours increased to 49 , skills laboratory practice to 18 , and clinical and field practice hours to 360 . Thus the total number of hours for SH/RH topics was increased from 395 hours before revisions to 427 hours after revisions. The teachers' practice handbook, which was developed for the purpose of ensuring that the educators used the same standards in education, and the teaching guidelines for subjects for the purpose of facilitating learning in practice and for students' to evaluate their own skills, were used in student practice.

For the purpose of increasing students' skills associated with SH/RH subjects, arrangement was made for the clinical skills laboratory to be left open to students at different hours under the supervision of consultant faculty members. Significant changes were not made in planning and implementing clinical and field practice at Baskent University and other hospitals and primary care facilities in the province.

\section{Findings}

The newly revised safe motherhood (prenatal, natal and postnatal care) curriculum subjects were taught in the 2005-2006 Fall semester. Compared to the previous year, 11 hours theory was given for prenatal, natal and postnatal care, after the revision the number of theory hours increased to 16. Safe motherhood topics were taught to a total of 33 students. A pre-test on the subject was given to the students. In addition to lectures, case study presentations, role-playing and visual education materials were used as teaching methods.

69 Journal of Practice Teaching \& Learning 8(2) 2008, pp.58-74. DOI: 10.1921/81133. @ wËb 
Table 1. Evaluation Of The Students' Opınıons Regardıng Safe Motherhood Skill Laboratory Practice

\begin{tabular}{lcccc}
\hline Question & Agree $\%$ & Disagree $\%$ & Not sure $\%$ \\
$n$ & $\%$ & $n$ & $\%$ & $n$ \\
\hline
\end{tabular}

1. The skills training

succeeded in its aim $\quad 21(61.7) \quad 3(8,8) \quad 10(29,5)$

2. The skill lab was

appropriate for training.

$22(64.8) \quad 3(8.8) \quad 9(26.4)$

3. The teaching methods

helped me to learn better. $\quad$ 29(85.2) _ _ _ $\quad$ 5(14.8)

4. There was enough appropriate

$\begin{array}{llll}\text { teaching equipment } & \text { 22(64.8) } & 6(17.6) & 6(17.6)\end{array}$

5. The attitude of the trainer

improved the atmosphere $\quad 31(91.1) \quad 1(3,0) \quad 2(5.9)$

6. The duration of the training

lab was long enough and skill 14(41.4) 11(32.2) 9(26.4)

For the role-plays the students were divided into seven groups. The subjects were given to the students by the faculty members before the sessions. The students prepared scenarios and performed them for their fellow students. After role-playing the subject under consideration, the observations and opinions of the actor and spectator students were discussed.

When the topic was completed a post-test questionnaire was administered and the students' level of success was evaluated. As a result of this evaluation, it was determined that the students' pre-test mean score was 32.8 and their post-test mean score was 90.8.

To facilitate the students' acquisition of skills under the scope of safe motherhood and to give every student an opportunity to practice again a daily skills laboratory practice was done which had not been done before the revisions were made. A station system was used in the skills laboratory practice. Three practice settings (prenatal care, natal, and postnatal care) were used at the same time during these practice times. The students were divided into three groups. The students practiced the procedures at every station for a specific period of time. In the practice

70 Journal of Practice Teaching \& Learning 8(2) 2008, pp.58-74. DOI: 10.1921/81133. (o wEb 
session, a faculty member gave a demonstration first, then the students repeated the procedure related to that practice station. The learning guidelines were used in the practice sessions.

After the skills laboratory practice the students' opinions were received. The majority of the students gave positive feedback, stating that the practice helped them meet learning objectives, the method facilitated learning, the faculty members' attitudes and behaviours created a positive educational atmosphere, and that it was beneficial for visual conceptualisation (Table 1). However, they also gave opinions that the number of students in the groups needed to be decreased, the educational tools and instruments need to be improved more, and the length of time needed to be increased for corrective measures to be taken.

After the skills laboratory practice a student practice examination was given using the learning guidelines that had been developed. In the examination, every student drew a number corresponding to a procedure. They were asked to carry out the procedure according to the correct steps. While the student was completing the procedure the faculty member and other students observed the procedure and evaluated whether or not the steps of the procedure had been followed correctly then after the practice examination the student $(n=34)$ was given feedback. The mean students' grades on the skills practice examination for safe motherhood were over 89.5 and no one dropped below $79 \%$.

After the changes in the curriculum the number of practice hours associated with safe motherhood was increased from 16 hours to 24 hours. Clinical practice was undertaken at three different hospital wards. At the same time, education and practice activities were also continued during home visits on appropriate SH/RH topics. After clinical practice the students' grades were given according to the care plans they prepared, their reports, and their performance on the wards. According to the assessment results the students grades were $80 \%$ and above; some reaching high scores in the 1990s.

No changes were made in the number of hours for female and male reproductive systems, included in the safe motherhood course. Changes in the adolescent SH/RH were that the theory hours increased from two theory hours to four theory hours after the revisions, and the practice hours from four to eight. The class on breast self examination and testicular self examination before the revisions was one hour for theory

71 Journal of Practice Teaching \& Learning 8(2) 2008, pp.58-74. DOI: 10.1921/81133. @ wËb 
and practice, but after the revision the theory increased to two hours and the practice to three hours. During practice every student conducted their own breast self examination or testicular self examination. The learning guidelines for every subject were used during practice. Every student was observed for correct practice.

Family planning topics were two hours theory and four hours practice before the curriculum was revised. After the revisions the theory hours did not change but two hours for skills practice were added and the total practice hours increased to eight. The students were also shown a CD on family planning methods and counselling subjects.

Findings indicate that the SH/RH revised curricula has led to enhanced results. Results of the Implementation in the Academic Year 2005-2006 suggests:

- By increasing practice hours on SH/RH topics the students had more practice time to improve their skills

- Variety was added to teaching methods

- Faculty members' motivation was increased

- Students' communication with faculty members increased

- Students' skills in project recommendation, planning, carrying out and presenting were developed.

- Skills of faculty members who had roles in the project were developed for education curricular development.

- Physical setting of skills laboratory was renovated.

- Educational materials (manikins, models, etc.) were increased for the skills laboratory.

- By increasing practice hours students had more opportunity to improve their skills.

- Positive feedback was given by students about the way the class was taught and their skills development.

- Guidelines were used in the development of educational materials.

- New manikins and models facilitated learning.

- Learning guidelines were used in skills development and they facilitated assessment.

- An improvement in students' skills in public education and school education was observed.

- A visual library was created on SH/RH topics. 


\section{Conclusion}

In this project, necessary changes were made to the existing nurse education programme in SH/RH. Accoridng to our evaluation, the information and skill levels of the students were increased and we achieved the practice learning goals set. The change in method and increased practice and skills time facilitated student learning, and additional benefit resulted in that the faculty members' motivation increased and this had a positive effect on the educational environment.

\section{References}

Akin A. (Ed.). (2003) Toplumsal cinsiyet, saglik ve kadın. [Social gender, health and women] Ankara: Hacettepe Üniversitesi Kadın Sorunları Arastırma ve Uygulama Merkezi (HUKSAM), Hacettepe Üniversitesi Yayınları

Aksayan, S. and Cimete G. (2000) Nursing education and practice in Turkey. Journal of Nursing Scholarship, 32, 2, 211-213.

Association for Medical Education in Europe (AMEE) (2005) Statement on the Bologna Process and Medical Education, World Federation for Medical Education.

Bebeis, H., Gül, R., Güngör, S., Kılıc, S., and Tugay, A. (2003) Üreme saghgl ve aile planlamast-egitim rehberi. [Reproductive health and family planning: Education guide] Ankara: Damla Yayıncllık.

Gordon, M. (2002) The North American Nursing Diagnosis Association Taxonomy II. in N. Oud (Ed.) ACENDIO 2002. Bern: Hans Huber

IPPF (2005) Models of Care Project. Linking HIVIAIDS treatment, care and support in sexual and reproductive health care settings: Examples in action. London, International Planned Parenthood Federation

Munich Declaration (2000) Nurses and Midwifes: A Force for Health. EURO/00/5019309/6-00600, 17th June

Nettina, S.M., and Mills, E. J. (2006) Lippincott Manual of Nursing Practice. (8th ed.). USA: Lippincott Williams \& Wilkins

Neyzi, O. and Yolsal, N.. (2002) Cinsel yolla bulasan enfeksiyonlar tanı ve tedavi rehberi. [Sexually transmitted diseases' diagnosis and treatment guidelines] İnsan Kaynagını Gelistirme Vakfı ve Birlesmis Milletler Nufus Fonu. s.1, İstanbul: Asama Matbaası

73 Journal of Practice Teaching \& Learning 8(2) 2008, pp.58-74. DOI: 10.1921/81133. @ wËb 
NNECP (2003) Nursing National Education Core Programme, Ankara: GATA Printing house

Olds, S., London, M., Ladewig, P.W., and Davidson, M.R. (2004) Clinical Handbook for Maternal-Newborn Nursing, Women's Health Care. (7th ed.) New Jersey: Pearson Education

Royal College of Obstetricians and Gynaecologists (RCOG) (2001) SH/RH in the Medical Curriculum, Report on an expert consultation. London: RCOG

Ministry of Health and European Commission Delegation Cooperation Programme-MHECDCP (2005) SH/RH In-Service Training Modules. Ankara The Turkish Republic Health Ministry (RTHM). (2004) Adolesanlarm / genclerin cinsel ve üreme saghgını etkileyen faktörler projesi. [Factors affecting adolescents/ young people's sexual and reproductive health] Ankara: Hacettepe Üniversitesi

The Turkish Republic Health Ministry (RTHM) (2005) Cinsel/saglik üreme saghgi, aile planlaması egitici rehberi (Sexual health/ reproductive health, family planning teacher's guide) Ankara: T.C.Sağlık Bakanlığı Ana Cocuk Saglıgı ve Aile Planlaması Genel Müdürlügü.

TDHS (2004) Türkiye Nufus ve Saglık Arastırması [Turkish Demographic Health Survey-TDHS] 2003] Hacettepe Üniversitesi Nüfus Etütleri Enstitüsü Ankara, Ekim

Ulusoy, F. (1998). Türkiye'de Hemsirelik Egitiminin Tarihsel Süreci (The Historical Process of Nursing Education in Turkey). Cumburiyet Universitesi Hemsirelik Yüksek Okulu Dergisi, [Cumhuriyet University Nursing School Journal] $2,1,1-8$

UNFPA (2004). Turkey: Celebrities kıck into actıon to curb violence against women. http://www.unfpa.org/endingviolence/html/pdf/chapter_turkey.pdf .8.3.2009

WHO (2001) Europian Strategy for Nursing and Midwifery Education. Guidelines for member States on the implementation of the strategy

WHO (2000) Community-Based Education of Health Personnel. Report of a WHO study Group. WHO Technical Report Series 746, 2000

74 Journal of Practice Teaching \& Learning 8(2) 2008, pp.58-74. DOI: 10.1921/81133. @ wEb 